\title{
Os clubes de remo em Porto Alegre (RS) e a recomposição de fronteiras de identidades culturais
}

CDD. 20.ed. 796.08

797.12

http://dx.doi.org/10.1590/1807-55092014000300441
Carolina Fernandes da SILVA*

Alberto de Oliveira MONTEIRO* Janice Zarpellon MAZO*
*Escola de Educação

Física, Universidade

Federal do Rio Grande do Sul.

\section{Resumo}

0 objetivo desta pesquisa é desvendar como, no cenário do remo, foram reorganizadas as fronteiras identitárias com a fundação do Club de Regatas Almirante Barroso, nas duas primeiras décadas do século XX. Para a efetivação deste estudo histórico foram utilizados principalmente os jornais porto-alegrenses que circulavam no período. A fundação do Club Barroso modificou o cenário do remo em Porto Alegre, no início do século XX. Até então, os demais clubes de remo demarcavam fronteiras identitárias entre teutobrasileiros e luso-brasileiros. 0 Club Barroso, diferentemente, congregou estes grupos de imigrantes e seus descendentes para a prática do esporte no Lago Guaiba. As fontes revelaram que esse clube de remo foi o primeiro da cidade a agrupar representações de identidades culturais luso-brasileiras e teuto-brasileiras.

Palavras-chave: História do esporte; Esportes náuticos; Remo; Clubes.

\section{Introdução}

A prática do remo inseriu-se no cotidiano dos porto-alegrenses na transição do século XIX para o século XX. Os primeiros clubes sul-rio-grandenses foram fundados por teuto-brasileiros (imigrantes alemães e seus descendentes): o Ruder Club Porto Alegre, em 1888, e o Ruder Verein Germania, em 1892. Estes clubes eram locais de sociabilidades e preservação de costumes e tradiçóes culturais de seus associados. Para a organizaçáo da prática esportiva, em 1894, estes clubes de remo fundaram o Comitê de Regatas, considerada a primeira federação esportiva do país ${ }^{1-3}$, onde se utilizava o idioma alemão em sua comunicação interna, como os clubes fundadores.

Em reação a hegemonia dos teuto-brasileiros, um grupo de luso-brasileiros instituiu o Grêmio de Regatas Almirante Tamandaré no ano de $1903^{4}$. Esta foi a primeira associação esportiva cujo idioma oficial era a língua portuguesa. Dois anos após, foi instaurado o "Club" de Regatas Almirante Barroso, onde luso-brasileiros e teuto-brasileiros conviviam e praticavam remo ${ }^{5}$.

O "Club" de Regatas Almirante Barroso, diferentemente dos clubes de remo que o antecederam reconfigurou as fronteiras identitárias no associativismo esportivo. As fronteiras não se constituem em uma estrutura fixa e rígida, mas sim elas se reconfiguram a partir das relaçóes dentro da própria associação esportiva e com os outros grupos sociais com os quais possuem relação. Para que isso aconteça, é necessário que haja elementos facilitadores, tais como: imigraçáo, emigração, arte, religiāo, literatura e o esporte. No caso deste estudo considera-se o esporte como sendo uma prática cultural basilar na recomposição das fronteiras identitárias entre os clubes.

Além disso, estimando que as relaçóes pessoais, sociais e culturais acontecem, a partir de uma construção simbólica, na esfera da subjetividade (significados, valores e ideais) e mais precisamente na escala da inter-subjetividade, entendemos que em alguma medida a leitura, o contato com o mundo e as representaçóes sociais, acabam por passar pelo crivo da interpretação. Em consequência, as ideias de imparcialidade e neutralidade absolutas ficam comprometidas, pois a apropriaçáo objetiva será sempre feita por uma subjetividade. Acolhendo o pensamento de CAMPBELL ${ }^{6}$, quando se tenta explicar um fato histórico, um evento, nunca chegamos a esgotar o seu significado, suas possibilidades. 
Perante essas consideraçôes iniciais, a presente pesquisa apresenta a seguinte questão norteadora: como no cenário do remo foram reorganizadas as fronteiras identitárias, com a fundação do "Club" de Regatas Almirante Barroso, nas duas primeiras décadas do século XX?

Este estudo compreende o esporte pela sua prática e pelos seus traços de exposição simbólica, podendo ser capaz de gerar um universo de relaçóes sociais, culturais e identitárias. Nesta direção, as fontes acessadas serão interpretadas a partir de duas categorias de análise: simbolismos e identidades, a fim de produzir uma versão histórica sobre o processo de construção identitária no campo esportivo porto-alegrense, por meio da organização de uma associação de remadores.

Os símbolos concorrem para dar uma explicação daquilo que a primeira vista é oculto à nossa racionalidade. JUNG ${ }^{7}$ declara que quando a mente explora um símbolo, é conduzida a ideias e reflexôes que estâo fora do alcance da razão. Por exemplo, quando racionalmente chamamos alguma coisa de divino, na verdade estamos dando um nome a algo que não nos sentimos preparados para explicar.

Para Gomes ${ }^{8}$, o símbolo se constitui na linguagem idealizada por alguns poetas. $\mathrm{O}$ mesmo autor ${ }^{8}$ declara que, muitas vezes, este é confundido com o signo. $\mathrm{O}$ signo é denotativo (o termo mão representa apenas a extremidade de um membro superior do corpo humano), entretanto, a mão divina, sendo motivada por uma crença ou fé, caracteriza-se pela conotaçáo. GoMEs ${ }^{8}$ acrescenta que o símbolo é para os simbolistas uma espécie de disfarce que pretende "encontrar a perfeita correspondência entre o mundo sensível e abstrato" (p.30).

Assim como todos os sistemas de símbolos - a arte, a dança, os rituais, os mitos, a linguagem e outros -, o esporte é um meio de expressão e de comunicação entre os seres humanos, as sociedades e de grupos identitários. Na expressão dos movimentos, na liturgia dos ritos, na história dos heróis e pela linguagem corporal, o esporte registra, simbolicamente, as marcas, os costumes e os comportamentos os quais refletem tanto as diferenças como as similitudes da dinâmica cultural. "Assim, enquanto universo de comunicação simbólica, o desporto tem como conteúdo principal da sua mensagem o mundo e o homem, sendo este o actor principal do jogo mundano"' (p.18).

Quando o sujeito se identifica com alguém, cultura ou instituição, ele percebe algo de si no objeto da sua identificaçấo e vice-versa. De igual maneira, pode-se descrever o modo como uma pessoa se qualifica junto ao clube esportivo: eu sou flamengo, eu sou gremista, eu sou colorado. MURAD ${ }^{10}$ interpreta da seguinte maneira: "Eu é a individualidade, Sou é a identidade profunda, Flamengo é a equipe; a coletividade" (p.12). Por essas observaçóes, podemos perceber como uma associaçáo esportiva pode catalisar tanto as identidades individuais como as coletivas: imagine o nível de sintonia e de unidade familiar percebida por alguém cuja vida foi de dedicaçáo ao clube caso seja ele fundador, sócio, dirigente, treinador ou atleta de um clube esportivo.

Para VALA ${ }^{11}$, a identificação grupal é um fator básico no processo de construçáa da identidade. Ainda seguindo o mesmo autor ${ }^{11}$, "as pertenças grupais duradouras e significativas são factores fundamentais na auto-representação pessoal, na medida em que contribuem para o sentido de distintividade e para o sentimento de valores pessoais" (p.106). Por isso, os clubes, em vários contextos históricos e culturais, ofereceram condiçôes necessárias para facilitar a cooperação, a construção e a interação entre indivíduos, coletividades e sociedades, com vistas à superação e soluçáo de conflitos e diferenças, podendo ser considerado como um facilitador e um mediador das fronteiras culturais.

Desta forma, o esporte é um meio de diálogo entre pessoas e povos. Quando vemos uma criança brincando com uma bola, parece que ela medita sobre o material, mas quando surge outro menino (ou menina), a bola passa a ser um instrumento de diálogo entre eles: uma conversa a dois, em grupo e em equipe. É lógico que, às vezes, do diálogo surge a discussão e, a partir desta, uma nova esfera de diálogo, a bola torna-se viva na tradução da língua do esporte.

Segundo AnTunes ${ }^{12}$, as práticas esportivas tem se revelado como ambientes propícios à constituição de identidades coletivas (grupos e nacionalidades), uma vez que permitem a conformação e experiências de integração social. Por essa reflexão, podemos considerar que uma das facetas da competiçáo esportiva, e de suas diferentes modalidades, é o de reunir condiçôes de aproximação de diversos grupos sociais, bem como o de configurar suas fronteiras identitárias e o de reconfigurar outras novas.

A partir do grau de sensibilidade dos grupos sociais a esta ou aquela prática, o esporte desenha os perímetros identitários. Nas duas primeiras décadas do século $\mathrm{XX}$, os diferentes grupos de imigrantes que viviam na cidade de Porto Alegre reconheciam, junto ao seu imaginário, que os seus heróis eram aqueles que realizaram os seus feitos - descobrimentos, conquistas e vitórias - através do uso de embarcaçóes e o lugar onde se dava essas realizaçôes eram o mar, os 
rios e as lagoas. A épica dos grandes acontecimentos navais torna-se, enquanto drama, uma das necessárias expressóes de identidade cujos sentimentos e emoçôes são concretamente vividos e sentidos.

Por isso, nos parece que não foi sem nenhum propósito que os grupos identitários teuto-brasileiros, luso-brasileiros e ítalo-brasileiros fundaram as

\section{Método}

O estudo considerou a linha de investigação de caráter histórico e, para isso, valeu-se das fontes impressas. As fontes impressas foram inquiridas no Arquivo Histórico de Porto Alegre Moysés Vellinho ${ }^{a}$, no Museu da Comunicação Hipólito José da Costa ${ }^{\mathrm{b}}$ e no acervo documental do "Club" de Regatas Almirante Barroso. Foram garimpadas notas e reportagens nas páginas de jornais de grande circulação em Porto Alegre no período demarcado para o estudo, considerando o título e o conteúdo, pois nas primeiras décadas do século $\mathrm{XX}$, os jornais estrearam as sessôes esportivas, que variavam em data de início, formato e localização.

Os jornais utilizados foram: "A Federação", "O Independente" e "Correio do Povo". Assim como os livros comemorativos: "Pequena História do Remo Gaúcho"1 e "Rio Grande do Sul Sportivo"13, que serviram de parâmetro para a pesquisa, porém analisados de forma diferenciada, por serem considerados documentos oficiais, que enaltecem as conquistas e deixam obscurecidas as dificuldades.

O principal critério para a seleção das reportagens foi a identificação de informaçóes acerca do "Club" de Regatas Almirante Barroso. Foram encontradas 121 reportagens sobre o clube, sendo nove extraídas do jornal A Federação, seis do jornal d' O Independente; e uma reportagem do Correio do Povo. No acervo do Club de Regatas Almirante Barroso foi encontrado um recorte de jornal com informaçôes relevantes, porém sem dados de identificação. Após a fase da coleta das

\section{Resultados}

\section{O "Club" de Regatas Almirante Barroso}

A prática do remo na cidade de Porto Alegre foi incrementada nas duas primeiras décadas do XX, em razão da fundação de associações de remadores, por imigrantes advindos da Europa e primeiras associaçóes de remo, na cidade de Porto Alegre. Desta forma, visavam reforçar laços de pertencimento com a sua comunidade. Um clube em particular estabeleceu uma estratégia diferente ao congregar luso-brasileiros e teuto-brasileiros, por meio da prática do remo: o "Club" de Regatas Almirante Barroso5.

fontes, passou-se para a codificação das informaçōes recolhidas. As notícias veiculadas em tais fontes foram fichadas e classificadas a partir do editorial, da reportagem e do conteúdo. Os critérios utilizados para o registro e a organização das fontes foram definidos a partir dos assuntos: fundação e identidade.

Após a escolha e constituição das fontes históricas, as informaçóes foram submetidas ao tratamento metodológico, conforme Barros ${ }^{14}$, Vainfas ${ }^{15}$ e BACELLAR $^{16}$. As fontes foram submetidas à técnica de análise documental, conforme os termos descritos por BACELLAR ${ }^{16}$. Esta técnica de análise destaca que após a análise propriamente dita dos documentos segue a fase do cruzamento de fontes.

Em um primeiro momento, este conjunto documental foi submetido a uma "análise de adequação"14, com vistas a verificar se as fontes propostas realmente estarão sintonizadas com o problema histórico proposto e se está compreendido em uma ideia de totalidade, onde não pode haver lacunas históricas. A partir destas análises, este "corpus" documental foi sujeito de uma apreciação com vistas a fornecer evidências, informaçôes e materiais passíveis de interpretação historiográfica. Com estas evidências, buscaram-se confrontaçóes externas às fontes, através da comparação de uma fonte com outras, ou do seu exame contra o fundo de outras séries de dados e evidências ${ }^{14}$. Além de ser interpretado a partir do referencial teórico escolhido. Os resultados da interpretação das informaçôes confrontadas são expostos nos tópicos que seguem. seus descendentes. Essas associações se configuraram como um ambiente propício para a construção de representaçôes de identidades culturais de imigrantes alemães, portugueses e italianos ${ }^{5,17-18}$.

No princípio do século XX, havia um domínio no cenário do remo de associações que produziam 
representaçôes de identidades culturais teutobrasileiras, como foi o caso dos precursores Ruder Club Porto Alegre e Ruder Verein Germania. Estas duas associaçôes fundaram a primeira entidade federativa brasileira, o Comitê de Regatas ${ }^{5,17}$. Em reação a esta hegemonia, instaurou-se uma associação de remadores, constituída por luso-brasileiros, o Grêmio de Regatas Almirante Tamandaré. A fundação desta associação representa um marco no acirramento das disputas identitárias na prática do remo em Porto Alegre. Neste período, representantes de diferentes grupos sociais teuto-brasileiros, luso-brasileiros e brasileiros -, antes distanciados por fronteiras simbólicas, aproximaramse para a organização de uma associação de remo - o "Club" de Regatas Almirante Barroso.

De forma semelhante ao Grêmio de Regatas Almirante Tamandaré, os fundadores do "Club" de Regatas Almirante Barroso adotaram uma denominação abrasileirada para batizar o clube. Porém, essa denominação mantinha uma ligaçáo forte com os luso-brasileiros. Conforme Hofmeister ${ }^{1}$, o clube adotou "nome genuinamente português, tendo seu patrono e grande almirante da esquadra brasileira, nascido em Portugal". Assim, este clube agregava representaçôes identitárias.

A primeira sugestão para a denominação do "Club" de Regatas Almirante Barroso foi Rowing Club Brasil, com termos em inglês e a cooptação com a nação brasileira. Caso escolhesse este nome se distanciaria das representaçóes identitárias existente nas demais associaçóes de remo porto-alegrenses. As duas primeiras palavras em inglês e a segunda que representa a naçáo brasileira, sugere que este clube nasceria em disputas para além das que ocorriam entre as identidades culturais brasileiras e teuto-brasileiras.

Curiosamente, entre os fundadores não havia sobrenomes de origem anglo-saxônica. Assim, possivelmente, a palavra em inglês utilizada, justifica-se porque durante muitos anos, os termos esportivos eram escritos neste idioma. Só mais tarde, já na segunda década do século $\mathrm{XX}$, os termos adotados no campo esportivo começam a ser aportuguesados. Presumivelmente, este movimento de adoção da língua portuguesa para termos até então em inglês ocorreu devido ao início de uma campanha de nacionalização durante a Primeira Guerra Mundial. No entanto, a palavra Brasil aponta um indício de que havia o intento de manter uma identidade que vinculasse a nova Pátria, fato que se confirmou, mas por meio de outras representaçóes identitárias.

Conforme o jornal $O$ Independente ${ }^{19}$, a fundação do clube aconteceu em 26 de fevereiro de 1905. Os membros da primeira diretoria do clube eram, em grande parte, de origem teuto-brasileirac ${ }^{c}$. O mesmo jornal noticiou a listagem de nomes da diretoria eleita para o próximo ano, a qual possuía uma maioria de sobrenomes luso-brasileiros ${ }^{20, d}$, em contraste com a diretoria do ano de fundação. Desta forma, o clube acenava para a recomposição identitária que, provavelmente, resultava de disputas internas.

$\mathrm{O}$ grupo de associados não era homogêneo, em virtude disso, sua identidade cultural foi sendo reconstruída, constantemente, no interior das trocas sociais, pois o "caráter flutuante que se presta a diversas interpretaçóes ou manipulações é característico da identidade" ${ }^{21}$. Esta característica do clube em misturar representaçóes culturais assinalou um diferencial em relação aos demais no remo.

Os dirigentes do clube, de diferentes procedências culturais, também herdaram distintas memórias culturais que lhe normatizaram condutas e seu imaginário em relação ao mundo. Assim, a organização do novo clube representou uma manifestaçáo da sua capacidade de manipular arranjos simbólicos ligados ao processo de construção de identidades - brasileira, teuto e portuguesa - a um só tempo e de maneira original e inovadora para a época.

Para $\mathrm{CuCHE}^{21}$ a identidade cultural exprime o resultado das diversas interaçóes entre o indivíduo e seu ambiente social, próximo ou distante. No início do século XX, a interação entre luso-brasileiros e teutobrasileiros começa a revelar indícios de cordialidade. Em 23 de março de 1903, o jornal O Independente ${ }^{22, e}$, publicou uma nota que indica um movimento social para desmistificar as contestas entre as comunidades. Nesta nota, era questionado se havia, realmente, motivos para temer os imigrantes alemães, que moravam em Porto Alegre, "descansem os nossos guarda-costas e officiosos vigilantes, não preocupa os brazileiros do Sul, congraçados, há mais de $3 / 4$ de século, com os allemães, cujo o caracter pacífico e leal jamais desmentirá a sua índole ordeira e moral"22.

Este registro, datado de 1903, teve seguimento, com mais ênfase, no ano de fundação da associação, em 1905, com uma sequência de cinco notas publicadas uma em continuação da outra, as quais foram assinadas pelo mesmo autor da primeira, que apenas assina as letras iniciais do seu nome, W.L., e se revela na última nota jornalística como Waldemar Ludwig ${ }^{23-27}$. No imaginário coletivo sul-rio-grandense "se imaginava que as regióes por eles habitadas poderiam servir como base para uma invasão alemâ"28 (p.67).

Anos antes à fundação do "Club" de Regatas Almirante Barroso, iniciou-se um debate entre uma 
parcela da opiniáo pública, brasileira e internacional, esta discussão continuou durante décadas. Os "francófilos" alertavam para um perigo alemão, e os "germanófilos" defendiam a posição contrária, com uma grande quantidade de textos escritos que refletem esses dois posicionamentos. $\mathrm{O}$ polêmico perigo era porque os teuto-brasileiros passaram a ser vistos como potencial cabeça-de-ponte ${ }^{\mathrm{f}}$ para uma aventura imperialista por parte de uma Alemanha, que havia chegado tardiamente ao mercado colonial ${ }^{28}$.

As notas "germanófilas" do jornal O Independente, defendiam os teuto-brasileiros domiciliados em Porto Alegre, como um grupo que auxiliou o Brasil, na sua colonização e com seu exército, em 1852, durante uma guerra internacional. Ainda acrescenta que após o conflito, combatentes adotaram o Brasil como pátria: "ficaram prestando a cooperação de suas actividade nas lettras, nas artes e nas industrias honrando a colônia allemâ"'22 (p.1) e que o suposto perigo alemão foi criado pela imprensa americana. Mas este perigo "não preoccupa os brasileiros do Sul, congraçados, há mais de $3 / 4$ de século, com os allemães, cujo caracter pacifico e leal jamais desmentirá a sua índole ordeira e moral" 22 (p.1).

De maneira irônica, o autor da nota dirige-se para o "francófilos", dizendo para descansarem os guarda-costas e oficiosos vigilantes. Contudo, finaliza se protegendo de qualquer possível manifestação contra ele, pois afirma que não possui nenhuma afinidade com a colônia alemã e escreveu inspirado nos sentimentos patrióticos e náo assina com seu nome, mas como "Um Veterano"22. O mesmo jornal, meses mais tarde, publica uma nova nota condenando a forma de patriotismo dos indivíduos que menosprezavam os teuto-brasileiros e que acreditavam em um perigo alemão. Além de fazer duras críticas aos luso-brasileiros, que se consideravam mais patrióticos que os teuto-brasileiros, os manda ficarem calados e "se ocuparem com alguma cousa de útil; de estudarem mais e fortalecerem seus músculos"29 (p.1).

Ao longo do texto, seu autor se assume teutobrasileiro e afirma que, muitas vezes, os teutobrasileiros são tão bons brasileiros "ou talvez melhor do que elles [germanófilos], que igualmente possui orgulho de ser descendente de uma raça, [...] que soube conquistar imorredouras glórias" ${ }^{29}$ (p.1). Possivelmente, os luso-brasileiros ao se associarem aos teuto-brasileiros na organização do "Club" de Regatas Almirante Barroso, concordavam com as ideias manifestas no jornal com relação a não haver motivos para temer os teuto-brasileiros. Ambos os grupos identitários tinham o Brasil como a sua segunda pátria, da mesma maneira que o patrono escolhido para nomear o clube: o Almirante Barroso.

$\mathrm{O}$ patrono Almirante Barroso não era de origem brasileira, mas adotou o Brasil como sua naçáo, pois defendeu a conservaçáo das fronteiras nacionais nas batalhas, como na do Riachuelo, umas das mais importantes da Guerra do Paraguai. A esquadra brasileira estava sob o comando em chefe do Almirante Tamandaré, e o Almirante Barroso era comandante de subdivisão ${ }^{30}$. Os almirantes navais brasileiros, escolhidos para nomearem as associaçóes de remo, eram considerados bravos heróis e atuaram juntos em uma batalha história. Segundo O Independente, consideravam que a "sua memória é digna de veneração de todos os brazileiros" ${ }^{\prime \prime}$ (p.1).

O "Club" de Regatas Almirante Barroso seguiu o exemplo do Grêmio de Regatas Almirante Tamandaré, e buscou a imagem de um herói naval nacional para assim também produzir a representação de clube vencedor. O desejo dos idealizadores do clube era possuir remadores campeóes. O "Club" de Regatas Almirante Barroso teve sua origem inicial com um grupo que tinha o intuito de organizar uma guarnição que disputasse, em igualdade com os outros clubes, o Wanderpreiss de $1905^{31}$.

A primeira equipe do clube, que conduziria o primeiro barco adquirido, foi composta por três irmãos remadores: Bertholdo Panitz, Osmundo Panitz, Walter Panitz, Henrique Huber, e o timoneiro, Frederico C. Gerlach. Estes remadores iniciaram a prática no Ruder Verein Germania, porém um conflito interno desencadeou a dissidência expressiva do clube, logo após o campeonato Wanderpeiss de 13 de novembro de $1904^{1,32}$. Havia uma divergência técnica entre o remador Osmundo Panitz, apoiado por alguns colegas e associados, "contra a orientação de Ludwing Semmler, o 'homem forte' do clube" ${ }^{32}$. Este treinador foi vencedor do Wanderpreiss de 1904, como timoneiro da guarnição do Ruder Verein Germania, tornando-se uma referência para os demais, pois era o detentor de um poder simbólico na associação.

O conflito estimulou a fundação do "Club" de Regatas Almirante Barroso. Uma associação, na qual, este grupo dissidente teria o poder de determinar o seu funcionamento e adotar representaçóes diferentes da associação, que pertenciam anteriormente. Como consta na ata de fundaçáo, o idioma sugerido para ser adotado era o vernáculo ${ }^{32}$, tanto que Henrique Huber tornou-se o instrutor e ministrava o treinamento em língua portuguesa.

De acordo com SILVA ${ }^{2}$, nos primeiros anos do século $\mathrm{XX}$, houve um conflito linguístico entre os remadores 
- luso-brasileiros apoiados por teuto-brasileiros que se consideravam mais brasileiros do que teutos - e o técnico, no interior do Ruder Verein Germania. O treinador ministrava as orientaçóes em idioma alemão durante os treinos, dificultando o entendimento daqueles que não dominavam o idioma, sendo esta a razão para a dissidência do grupo de remadores e que resultou na fundação do "Club" de Regatas Almirante Barroso. Desta forma, fica evidente que a associação originou-se a partir de um conflito identitário entre representações de identidades culturais luso-brasileiras e as teuto-brasileiras.

Alguns fragmentos de identidades culturais teuto-brasileiras permaneciam no clube, como por exemplo, o costume de promover atividades sociais, os "pic-nics" e "quermesses". Conforme Daudt ${ }^{33}$, "pic-nics" sáo passeios campestres, em locais aprazíveis, fora do tumulto da cidade, na beira de rios, em florestas ou no campo. O "Club" de Regatas Almirante Barroso promoveu um "pic-nic" para seus associados e divulgou o convite n' $A$ Federaçãa $0^{34}$. Neste "pic-nic" foram vendidos ingressos para uma "kermesse" organizada em benefício do clube ${ }^{35}$. As "kermesses" são caracterizadas como festas oriundas de costumes europeus, principalmente da 'Bavaria'g, geralmente aproveitadas para fins filantrópicos ${ }^{33}$.

No "Club" de Regatas Almirante Barroso, também se identificou representaçóes "brasileiras", como a escolha do idioma oficial do clube e dos nomes dos barcos. O nome do primeiro barco adquirido pelo clube foi o "Aquidaban", em homenagem ao navio da marinha brasileira, que naufragou um ano após a fundação do clube e foi noticiado pelo $A$ Federaçã $0^{36}$. $\mathrm{O}$ barco foi construído pelos integrantes da guarnição, com a finalidade de atender o treinamento dos remadores ${ }^{1}$. Os remadores tinham conhecimento com relação ao funcionamento e arquitetura dos barcos de competiçáo no remo, a qual foi adquirida no período que atuaram no Ruder Verein Germania. Por outro lado, a construção do barco evidencia a falta de recursos financeiros para comprar, assim como a pressa para início das atividades do clube. Outros clubes de remo encomendavam barcos construídos no exterior.

O clube instalou-se inicialmente em um pequeno chalé cedido por um dos fundadores, Henrique Huber. A nova sede do clube, inaugurada em 1908, segundo o jornal Correio do Povo ${ }^{37}$ foi "construída no littoral do Caminho Novo [já Rua Voluntários da Pátria], fronteiro a Rua 7 de abril", beirava o local onde o esporte era praticado, o lago Guaíba que contorna Porto Alegre. Também tinha um antigo galpão, local onde foi construído o barco, de acordo com o modelo dos alemães. O galpão servia para guardar, provisoriamente, o material náutico e era o vestiário dos remadores. Talvez, estas condiçóes precárias tenham favorecido para que o "Club" de Regatas Almirante Barroso fosse considerado a primeira associaçáo popular de remo em Porto Alegre, já que as outras associaçóes eram identificadas como sendo aristocratas ${ }^{1,13}$. Contudo, as instalaçôes e equipamentos simples não impediram que o clube se destacasse nas regatas.

\section{As disputas no remo}

Os idealizadores do clube, destacando-se os irmãos Panitz, o timoneiro Gerlach, e o remador Henrique Huber compunham a guarnição que conquistou o primeiro prêmio Wanderpreiss, já no ano de fundação, em 1905, e no ano seguinte ${ }^{38}$. No estudo de SILVA ${ }^{5, h}$ há uma fotografia que registra a primeira vitória do clube no Wanderpreiss, a qual evidencia o valor dado ao timoneiro: "o troféu está no centro, mais próximo do timoneiro, comandante da tripulação, posições mais usuais em fotografias de guarniçôes campeãs"s (p.84). Os timoneiros eram considerados os principais responsáveis pelas conquistas das guarniçóes.

No jornal $O$ Independente ${ }^{38}$ foi publicada uma fotografia que historiou a chegada da regata Wanderpreiss de 1905. Esta imagem, além de registrar a competiçáo entre os clubes de remo, permitindo ver o local da disputa próximo a maioria das sedes das associaçóes de remo na Rua Voluntários da Pátria, também mostra as imediações do lago Guaíba, que na época, tinha poucas casas e alguns trapiches que propiciavam o acesso dos barcos para a prática do remo. Ainda, a fotografia mostrou dois jovens espectadores sentados em uma pedra, com os olhos vidrados nos barcos, destacando-se no primeiro plano da imagem o barco Aquidaban do "Club" Barroso. Os jovens pareciam admirar o cenário do remo, na qual não podiam fazer parte, pois, neste período, não era permitida a participaçáo de meninos na prática do remo nos clubes sul rio-grandenses.

Faz-se a ressalva que o troféu Wanderpreiss somente era empossado ao clube que conquistasse três vitórias. No ano de 1908, o "Club" de Regatas Almirante Barroso conquistou a terceira vitória, com a presença do remador Christiano Matte Filho, que substituiu Henrique Huber, e assim conquistou definitivamente o troféu. Tal conquista consolidou o "Club" Barroso como a melhor associação de remo de Porto Alegre, em apenas quatro anos de participaçáo no campeonato, perdendo apenas em 1907, para o Grêmio de Regatas 
Almirante Tamandaré. As guarnições (equipes) que conquistaram os três prêmios para o "Club" Barroso e, assim oportunizaram que levasse o troféu para a sua sede, era, basicamente, composta pelos irmãos Panitz. Os irmãos Walter Panitz, Bertholdo Panitz, Osmundo Panitz eram uma constante nas guarniçóes principais, assim como o timoneiro F.C. Gerlach variando, apenas, um dos remadores 5 .

SiLva ${ }^{5}$ realizou uma análise iconográfica do quadro fixado na parede da secretaria do "Club" de Regatas Almirante Barroso, no qual consta uma descrição histórica do prêmio Wanderpreiss com o registro das seis vitórias ${ }^{j}$ conquistadas nos primeiros 20 anos de existência do "Club" Barroso. Neste quadro, também constam imagens e descrições das guarniçóes vencedoras. A guarnição aparece vestida com o uniforme da época, proposto pelo instrutor Henrique Huber: boné azul com tiras brancas, calção azul marinho, meias compridas pretas e sapatos de lona, camisa decotada com mangas curtas, listas azuis e brancas.

$\mathrm{O}$ quadro também revela imagens que permitem ressaltar a estrutura corporal dos remadores - "como é possível visualizar nas pernas de Osmundo Panitz, sentado do lado direito, na foto da guarnição campeã de $1905 " 5$ (p.85). As pernas deste remador possuíam volume muscular, visualmente contrária ao padrão de beleza da época. Esta mudança corporal proporcionada pela prática do remo pode ter auxiliado em uma mudança na estética corpórea considerada ideal no período. Um conceito que envolvia o remo que o considerava prejudicial à saúde, em um período em que as atividades intelectuais possuíam um grande valor.

O quadro fixado na parede da sede do "Club" de Regatas Almirante Barroso também cristaliza a memória do clube. O emblema da associação está estrategicamente localizado no lado esquerdo do peito, onde, simbolicamente, fica o coração. Os signos no emblema apresentam dois remos atravessados, uma âncora e as iniciais: C.R.A.B - "Club" de Regatas Almirante Barroso5. Esta composição do emblema era semelhante ao do Grêmio de Regatas Almirante Tamandaré. Os fundadores das associaçôes utilizaram a âncora e a ressignificaram como um símbolo de segurança para os remadores, que se sentiam excluídos do cenário do remo por sua identidade cultural, diferente da imposta pelo grupo dominante nas associaçóes com representaçôes identitárias teuto-brasileiras. O quadro e sua localização não só representa o valor simbólico desta disputa no imaginário coletivo dos clubes de remo, mas também a conquista da intenção dos fundadores do clube, que desejavam superar os já existentes.
O Wanderpreiss voltou a ser conquistado pelo "Club" de Regatas Almirante Barroso em 1910, com o barco Amazonas e uma nova guarnição: João Ibanez, Guilherme Weidlich, Walter Teichmann, Henrique Volkmann e no timão, Henrique Huber, que passa de remador a timoneiro ${ }^{13}$. As denominaçôes dos barcos do "Club" de Regatas Almirante Barroso também seguiam uma tradição, estando ligadas a nomes que representavam uma identidade cultural brasileira, como o Aquidaban e o Riachuelo, nomes de barcos da marinha brasileira, assim como o Amazonas, também denominação de um Estado brasileiro. Desta maneira, os "Club” de Regatas Almirante Barroso representava em seus barcos a sua ligação com o órgão náutico do governo, defensor do Brasil nos mares. A partir de 1915, a competição chamada Wanderpreiss transformou-se no campeonato de remo do Estado, mas a alcunha Wanderpreiss continuou entre os clubes de remo .

O "Club" de Regatas Almirante Barroso e o Grêmio de Regatas Almirante Tamandaré se revezaram nas conquistas desta competição, até o ano de 1924. As competiçóes tinham uma atmosfera propícia também para lutas de representaçóes de identidades culturais. $\mathrm{O}$ remo era impregnado com ideias de competição, disputa e combate, ligadas ao padrão de virilidade masculina, criando, assim, um imaginário em torno do esporte, distante da construção cultural da feminilidade.

Conforme as mudanças corporais que tal prática proporcionava para seus praticantes, as mulheres eram mantidas à distância da prática esportiva. Para elas os espaços permitidos para serem vistas, inicialmente, era na condição de espectadoras das regatas. Os conceitos que revestiam o remo pareceram restringir a prática aos homens e, no mesmo movimento, inviabilizavam a prática às mulheres. Até o início do século XX, as mulheres definiam seu espaço no cenário, por meio da sua presença marcante nas arquibancadas e nos barcos a vapor onde estavam os espectadores das regatas.

Um segundo conceito estava relacionado ao pudor da prática: os remadores usavam pouca quantidade de roupa, o que já ocasionava críticas. Os trajes usados pelos remadores eram considerados demasiados abertos, pois deixavam partes do corpo mais à mostra, como pernas e braços. Para as mulheres porto-alegrenses, estes trajes de banho eram considerados sumários e, assim, desvirtuados da cultura da época, que pregava que quanto mais a pele era mostrada, mais estava ligada a um erotismo latente. Se para os homens o remo já não era indicado como prática esportiva, pois os tornava fortes e 
com a musculatura desenvolvida, "o que era pouco usual em uma época onde se valorizavam os tipos físicos magros e fracos"39 (p.5), para as mulheres era totalmente contra indicado, acusado de que transfiguraria o corpo feminino, masculinizandoo. Porém, o "Club" de Regatas Almirante Barroso também rompeu a supremacia dos homens na prática do remo ${ }^{\mathrm{k}}$.

O "Club" de Regatas Almirante Barroso desencadeou mudanças no cenário esportivo do remo em Porto Alegre, pois foi a primeira associaçáo de remo a reunir representaçôes de identidades culturais luso-teuto-brasileira ${ }^{1}$. Além disso, era considerada a primeira associação popular de remo ${ }^{13}$. E, ainda foi a primeira a permitir a prática do esporte por mulheres'. De acordo com LICHT ${ }^{2}$ e SILVA ${ }^{5, \mathrm{~m}}$, em dois de fevereiro de 1907, foi realizada uma regata interna no "Club" de Regatas Almirante Barroso, em homenagem à Nossa Senhora dos Navegantes, quando foi disputada a primeira regata entre mulheres na cidade. Este evento não foi noticiado pelos jornais da época, apesar de notícias sobre o remo serem evidenciadas nos jornais no período. Isto revela a obscuridade que era imposta à prática do remo por mulheres.

Ao olhar o cenário do remo percebe-se que este esporte oportunizou para as mulheres visibilidade para além dos espaços privados. No início da instauração das associaçóes na cidade, elas estavam relegadas a participaçōes acessórias. No Ruder Club Porto Alegre destacaram-se em auxiliar financeiramente a compra dos primeiros barcos, bem como ceder seu nome para o batismo destes. Nas demais associaçóes, amadrinhar os barcos e embelezar as arquibancadas durante as regatas eram as suas atribuiçōes ${ }^{40}$. Desta

\section{Discussão}

O remo está entre os primeiros esportes que foram institucionalizados em clubes no Brasil. Melo ${ }^{39}$ investigou os primórdios deste esporte no Rio de Janeiro e o estudo de LUCENA ${ }^{42}$ revelou outras configuraçóes desta prática também no Rio de Janeiro. No Maranhão, a história do remo foi registrada por $\mathrm{VAZ}^{43}$. No sul do Brasil, na capital do Estado de Santa Catarina, em Florianópolis, o início da prática do remo foi revelada por ZANCA ${ }^{44}$. O levantamento de estudos feitos sobre a história do remo em diferentes regiôes do país possibilita dar a ver o remo como uma prática cultural bastante difundida em diversas forma, as associaçóes de remo eram utilizadas como pretexto para que pudessem abranger espaços para além das suas casas: "o desenvolvimento do comércio, dos lazeres, do conjunto de equipamentos urbanos que as chama cada vez mais a transpor a soleira da porta" ${ }^{\prime 11}$ (p.76).

Logo, as diferenças do papel das mulheres em relaçáo aos homens modificam-se devido à cultura imigrada com as famílias teuto-brasileiras e incorporada à cultura local. A participação das mulheres nas práticas corporais/esportivas ocorria como forma de manutenção da identidade e diferenciação de outros grupos étnicos, em associaçóes esportivas com identidades culturais teuto-brasileiras. O "Club" de Regatas Almirante Barroso incorporou essa representação teuto-brasileira à sua identidade cultural, não apenas por fazer parte da memória cultural de alguns de seus fundadores, mas, principalmente, por diferenciá-los ainda mais das associaçôes já existentes. As primeiras associaçôes esportivas teuto-brasileiras, fundadas em Porto Alegre, tinham como característica a participação das mulheres em práticas corporais/esportivas, como na ginástica, no boláo e no tiro ao alvo. Todavia este processo foi gradual e no caso do remo, as mulheres iniciaram a sua participação, aproximadamente, 20 anos após a sua instauração na cidade.

Assim como as mulheres conquistaram certo espaço na prática do remo no "Club" de Regatas Almirante Barroso, os homens jovens também organizaram uma guarnição, chamada "Os Filhotes do Barroso" que disputava regatas com jovens remadores do Ruder Verein Freundschaft (associação juvenil de remo, fundada em 1906 por teuto-brasileiros). Portanto, o clube também foi um dos pioneiros a oportunizar a prática do remo para jovens.

regiốes do país no início do século XX. Além disso, realça a relevância desta pesquisa, sobre a história do remo em Porto Alegre, e sua contribuição para estudos no âmbito da História do Esporte no Brasil, já que os demais estudos não buscam a análise de representações de identidades culturais constituídas (simbolicamente) a partir da prática esportiva do remo, mas em como o campo do esporte se desenvolveu socialmente em diferentes locais do país e quando os primeiros clubes foram instaurados.

Assim, vamos ao encontro do pensamento de $\operatorname{DiAs}^{45}$ (p.266), quando afirma que os estudos em 
História do Esporte atribuem "pouca importância aos modos de uso e classificação mobilizados pelos vários grupos sociais que se enfrentavam à época para a legitimação de suas respectivas práticas". Na perspectiva de assinalar que a prática do remo fazia parte do cotidiano dos porto-alegrenses desde final do século XIX, e que tal cenário esportivo foi palco de disputas identitárias, especialmente no princípio do século XX, foi realizado o estudo sobre o caso do "Club" de Regatas Almirante Barroso. Segundo $\mathrm{MeLO}^{46}$ (p.36), os clubes que chegaram ao Brasil com os imigrantes, eram espaços privilegiados de encontro e autoidentificação. E eram constituídos pela secreta intenção de resgatar cenários de origem e de fronteiras de vivência e de convivência, onde os símbolos norteadores brotavam da sua identidade e o seu pertencimento.

O remo, no início do século XX, era uma prática esportiva difundida em vários países. Teve uma importante influência nos costumes e hábitos da população, além de ser o primeiro a estabelecer definitivamente a ligação entre o esporte, a atividade física e as preocupações com a saúde ${ }^{46}$.

No Brasil, desde o século XIX, a prática do remo ocupava o noticiário dos jornais da capital do país ${ }^{42}$ e, paulatinamente, a prática se disseminou pelo país. Anteriormente a fundação do "Club" de Regatas Almirante Barroso, já havia diversos movimentos de difusão da prática do remo com barcos adaptados, como escaleres e canoas.

O Rio de Janeiro, capital do país no período, era favorecido por muitas praias e o mar era o palco da prática do remo ${ }^{42,46}$. Entretanto, isto ocorreu por meio de grupamentos que se formaram na cidade, mas nunca constituíram uma sociedade com a prática regular do desporto. O primeiro clube de remo, de acordo com Hofmeister ${ }^{1}$, foi fundado no Rio do Janeiro, no fim do século XIX.

O remo já existia na cidade do Rio de Janeiro

desde a década de 1870, mas o seu desenvolvi-

mento se dava a passos lentos, principalmente

porque estava ligado a uma prática ainda não

completamente aceitável no contexto sócio-

cultural do Rio de Janeiro da época ${ }^{47}$ (p.5).

Segundo $\mathrm{MeLO}^{39}$, o primeiro clube foi fundado na cidade do Rio de Janeiro foi "Club" Guanabarense, que apesar de ter sua fundação em 1874, realizou sua primeira regata em 1876 . Na cidade de Florianópolis, LichT $^{2}$ diz que a primeira regata ocorrida foi em 1861, ainda quando esta se chamava Desterro. Organizada pela a Sociedade de Regatas, esta regata ocorreu com barcos escaleres e baleeiras. Apenas em 1902, foi fundado o "Club” de Regatas 29 de abril.
Esta data confronta-se com o estudo de $Z_{A N C A}{ }^{44}$, de que o "Club" de Regatas 29 de abril foi fundado em 1903 e considerado o primeiro clube de remo da cidade, ligado à federação do remo do Rio de Janeiro. Demonstra-se um confronto entre três informaçōes divergentes e a emergência de mais estudos sobre o assunto. No nordeste do país, especificamente no Maranhão, houve o tentame de implantar o remo, buscando a utilização dos rios Anil e Bacanga, foi criado o Clube de Regatas Maranhense, em 1903. Todavia, a ideia não se consolidou, faltaram recursos para aquisição das embarcaçóes apropriadas, assim como o apoio do comércio e das autoridades estabelecidas. Quando, em 13 de setembro de 1908, houve uma nova tentativa, voltou-se a falar na implantação do remo, no Estado, chegando a ser organizada uma competição, porém a reimplantação do clube só se realizou em $1909^{43}$.

No Rio Grande do Sul, conforme $\operatorname{LichT}^{2}$ (p.105), em 1875 ocorreu a fundação, em Pelotas, do primeiro clube de remo no Rio Grande do Sul, o "Club" de Regatas Pelotense. Já em Porto Alegre, onde o local da prática era no lago Guaíba, os clubes de remo fizeram as suas primeiras atuações no fim do século XIX, quando surgiram as primeiras associaçóes. Todavia, foi no início do século XX que esta prática já institucionalizada se disseminou e ganhou espaço em notas de jornais, que noticiavam a rotina dos clubes de remo, principalmente na capital do Estado.

$\mathrm{Na}$ capital sul-rio-grandense, os clubes de remo eram locais onde os imigrantes buscavam sua socialização e exerciam sua identidade vinculada ao país de origem, desta forma geravam representações de identidades teuto-brasileira e luso-brasileiras e constituíam um mosaico identitário neste cenário esportivo. A fundação do "Club” de Regatas Almirante Barroso se consolidou graças a iniciativa de egressos de clubes já existentes. Esse clube de remo, diferentemente dos anteriormente fundados, agrupava identidades culturais luso-brasileiras e teuto-brasileiras, embora seu nome inspirou-se em um reconhecido almirante da esquadra brasileira, nascido em Portugal.

Deste modo, podemos dizer que ninguém se livra das suas origens, mesmo quando aparenta esquecê-las, as pessoas, pela imaginação e pela expressão simbólica - e como que prestando contas do caminho percorrido -, aqui e ali, vão demarcando espaços e fronteiras numa morfologia simbólica que acenam para a ampliação dos processos de integração e socialização: uma constelação de aspirações, limitações e de inúmeras possibilidades. 


\section{Notas}

a. O Arquivo Histórico de Porto Alegre Moysés Vellinho reúne, preserva e divulga cerca de um milhão de documentos que constituem a mais importante fonte de pesquisa sobre a cidade. Sob sua guarda estão documentos datados de 1764, que registram a formaçáo de Porto Alegre, jornais e revistas que relatam seu cotidiano, além de relatórios, projetos, mapas, plantas e correspondências que mostram a política das administraçóes municipais ${ }^{48}$.

b. O Museu da Comunicação Hipólito José da Costa concentra o arquivamento de jornais e revistas do Rio Grande do Sul, que poderam ser usadas nesta pesquisa. Este museu tem como missão pesquisar, recolher, classificar e conservar acervos das diversas áreas da comunicação social produzidas nos níveis regional, nacional e internacional para fins de estudo, educação e lazer. Assim como adquirir, documentar, preservar, expor e divulgar a história e as transformaçóes tecnológicas, sócio-políticas, econômicas e culturais, incluindo formas e fontes comunicacionais originárias do Rio Grande do Sul ${ }^{19}$.

c. Presidente: Pedro Adams; vice-presidente, Germano Sperb; $1^{\circ}$ secretario, Luiz Gonçalves Fortes; 20 dito, Walter Kionka; thesoureiro, Oscar Wiedemann; adjuncto do thesoureiro, Arthur Luiz Schwartz; instructor, Henrique Huber e Edmundo Seibert; timoneiros, Bertholdo Panitz, Osmundo Panitz; zeladores Engelbert Kirchhof ${ }^{19}$ (p.3).

d. Presidente, Dario Canabarro; vice-presidente, F. Nabuco Varejão; $1^{\circ}$ secretario Joaquim Ilha da Fontoura; $2^{\circ}$ secretario, Augusto Vogel; $1^{\circ}$ thesoureiro, Oscar Wiedemann; $2^{\circ}$ thesoureiro, Carlos Bohrer; instructor, Henrique Huber; zelador, Osmundo Panitz ${ }^{18}$ (p.2).

e. Cabe ressaltar, que o editor deste jornal era o luso-brasileiro Otaviano M. de Oliveira, o mesmo que expressou revolta quanto à nacionalização do Ruder Club Porto Alegre, no jornal Gazetinha, em $1895^{50}$.

f. É uma terminologia militar referente a uma posição provisória ocupada por uma força militar em território inimigo, rio ou mar, tendo em vista um posterior avanço ou desembarque.

g. Bavaria, em Latim; Baviera, na língua portuguesa; "Bayern”, em alemão, é um dos Estados livres da Alemanha.

h. Para mais informaçóes consultar: Silva CF. O remo e a história de Porto Alegre, Rio Grande do Sul: mosaico de identidades culturais no longo século XIX [dissertação]. Porto Alegre (RS): Universidade Federal do Rio Grande do Sul; 2011.

i. No ano de 1908 foi instituído outro clube de remo em Porto Alegre: Club Cannotiere degli Abruzzi aglutinando majoritariamente imigrantes italianos e seus descendentes. Esta associação de remadores promoveu unicamente a prática do remo e da natação, e por meio dessas práticas esportivas constituiu-se em espaço de preservação de identidade étnica-cultural dos ítalo-brasileiros ${ }^{13,51}$. Algumas das representaçóes e práticas culturais produzidas pelo "clube de remo dos italianos" em Porto Alegre são similares aquelas construídas pelo Palestra Itália, um clube de futebol identificado com os imigrantes italianos em São Paulo, conforme revela a pesquisa de Araújo ${ }^{43}$. Por exemplo, o Club Cannotiere degli Abruzzi foi forçado ao abrasileiramento mudando o nome para Grêmio de Regatas Duque de Caxias em 1942, no mesmo ano em que o Palestra Itália, adotou o nome de Sociedade Esportiva Palmeiras. Além desta, outras informaçôes relevantes sobre a relação entre o associativismo e etnicidade no campo esportivo brasileiro são apresentadas na pesquisa precursora de ARAújo ${ }^{52}$.

j. Nos anos de 1905, 1906, 1908, 1910, 1921, 1924.

k. Em 1917 foi fundado outro clube de remo em Porto Alegre pela iniciativa de luso-brasileiros: "Club” de Regatas Vasco da Gama. Logo nos primeiros anos já participou da disputa do Wanderpreiss. Este clube que se mantem em atividade até os dias atuais, sempre promoveu a prática do remo e de esportes aquáticos diferentemente do "Club” de Regatas Vasco da Gama fundado em São Paulo, que além do remo introduziu a prática do futebol ${ }^{53}$.

1. Apesar deste tema não estar entre os objetivos deste estudo não podemos fechar nossos olhos para estas informaçóes. m. SILVA ${ }^{5}$ expóe imagens da primeira regata entre mulheres noticiada, ocorrida em um campeonato interno do clube, em 1907.

\section{Abstract}

\section{Rowing clubs in Porto Alegre (RS) and cultural identities}

The objective of this research is to unveil, in the scenario of rowing, were reorganized the boundaries of identity with the founding of the Club de Regatas Almirante Barroso, in the first two decades of the twentieth century. For the execution of this historical study, were primarily used the newspapers circulating in the period, in Porto Alegre. The Foundation of the Club Barroso modified the scenario of rowing in Porto Alegre, in the early 20th century. Until then, the remaining rowing clubs marked borders 
of identity between Brazilians and in 1867. The Club, unlike, brought together these groups of immigrants and their descendants for the practice of sport in Guaiba Lake. The sources revealed that this Rowing Club was the first of the city the Group representations of Luso-Brazilian and German cultural identities.

KEY WORDS: History of sport; Water sports; Rowing; Clubs.

\section{Referências}

1. Hofmeister C. Pequena história do remo gaúcho. Porto Alegre: CORAG; 1979.

2. Licht H. O remo através dos tempos. Porto Alegre: CORAG; 1986.

3. Melo V. Dicionário do esporte no Brasil: do século XIX ao início do século XX. Campinas: Autores Associados; 2007.

4. Silva C, Mazo, J. Grêmio de regatas Almirantes Tamandaré: memórias da fundação do primeiro clube de remo "brasileiro" em Porto Alegre (1903-1923). Rev Arq Mov. 2009;5.

5. Silva C. O remo e a história de Porto Alegre, Rio Grande do Sul: mosaico de identidades culturais no longo século XIX. Porto Alegre: Universidade Federal do Rio Grande do Sul; 2011.

6. Campbell J. Mito e transformação. São Paulo: Ágora; 2008.

7. Jung C. O homem e seus símbolos. Rio de Janeiro: Fronteira 2008.

8. Gomes AC. O simbolismo. Sáo Paulo: Ática; 1994.

9. Costa E. História ilustrada de Porto Alegre. Porto Alegre: Já; 1997.

10. Murad M. Das relaçóes, fronteiras e questionamentos entre violência e futebol: fundamentos antropológicos, sociológicos e estudo-de-caso no Club de Regatas Vasco da Gama (Rio de Janeiro/Brasil) e no Futebol Clube do Porto (Porto/ Portugal). Porto: Universidade do Porto; 2004.

11. Vala J. Diferença e semelhança: o peso da identidade. In: Appadura A, Ribeiro AP, organizadores. Podemos viver sem o outro? As possibilidades e os limites da interculturalidade. Lisboa: Ediçóes Tinta-da-China; 2009.

12. Antunes F. Com brasileiro não há quem possa: futebol e identidade nacional em José Lins do Rego, Mário Filho e Nelson Rodrigues. São Paulo: Editora UNESP; 2004.

13. Rio Grande do Sul Sportivo. Álbum. Porto Alegre: Oficinas gráficas da Livraria do Globo; 1919.

14. Barros JDA. A fonte histórica e seu lugar de produção. Cad Pesq CDHIS. 2012;25:23.

15. Vainfas R. História das mentalidades e história cultural. In: Cardoso CF, Vainfas R, editores. Domínios da história: ensaios de teoria e metodologia. Rio de Janeiro: Elsevier; 1997. p.38.

16. Bacellar C. Fontes documentais: uso e mau uso dos arquivos. In: Pinski C, organizador. Fontes históricas. São Paulo: Contexto, 2010. p.23-80.

17. Mazo J. A emergência e expansão do associativismo esportivo em Porto Alegre (1867-1945): espaço de representação da identidade cultural brasileira. Porto: Universidade do Porto; 2003.

18. Frosi T, Mazo J. O abrasileiramento do clube de remo dos italianos em Porto Alegre nas décadas de 1930-1940. Movimento. 2012;18.

19. Club de Regatas. A Federação, Porto Alegre. 2 mar. 1905:2.

20. Club de Regatas. O Independente, Porto Alegre. 15 mar. 1906.

21. Cuche D. A noçáo de cultura nas ciências sociais. Bauru: EDUSC; 1999.

22. Perigo Allemão. A Federação, Porto Alegre. 23 mar. 1903;4:2.

23. O Perigo Allemão I. A Federação, Porto Alegre. 9 fev. 1905.

24. O Perigo Allemão II. A Federação, Porto Alegre. 12 fev. 1905.

25. O Perigo Allemão III. O Independente, Porto Alegre, 16 fev. 1905.

26. O Perigo Allemão IV. A Federação, Porto Alegre. 19 fev. 1905.

27. O Perigo Allemão V. O Independente, Porto Alegre. 23 fev. 1905.

28. Gertz R. O perigo alemão. Porto Alegre: Editora da Universidade/UFRGS; 1991.

29. Patriotismo. O Independente, Porto Alegre. 14 jun. 1903.

30. Homenagem Almirante Barroso. O Independente. Porto Alegre, 11 jun. 1911.

31. Club. Acervo de jornais do Clube de Regatas Almirante Barroso; sem data.

32. Licht H. O Clube de Regatas Almirante Barroso. Porto Alegre; 2003. 
33. Daudt J. Brasileiros de cabelos loiros e olhos azuis. Porto Alegre: Catos; 1952.

34. Club Almirante Barroso. A Federação, Porto Alegre. 25 fev. 1906:2.

35. Pic-nic. A Federação, Porto Alegre. 8 mar. 1906:4.

36. Desastre no Jacuecanga. A Federação, Porto Alegre. 3 fev. 1906.

37. Club Almirante Barroso. Correio do Povo, Porto Alegre. 4 jul. 1908.

38. Gig. O Independente, Porto Alegre. 2 dez. 1905.

39. Melo VA. Cidade sportiva: primórdios do esporte no Rio de Janeiro. Rio de Janeiro: Relume Dumará; 2001.

40. Silva C, Pereira E, Mazo J. Uma abordagem historiográfica sobre a participação das mulheres nas associaçóes de remo em Porto Alegre. Rev Didát Sist. 2010;12.

41. Schpun M. Beleza em jogo: cultura física e comportamento em São Paulo nos anos 20. São Paulo: Bom Tempo; 1999.

42. Lucena R. O esporte na cidade: aspectos do esforço civilizador brasileiro. Campinas: Autores Associados; 2001.

43. Vaz L. Remo no Maranhão, 1900-1929. In: Da Costa L, editor. Atlas do esporte no Brasil: atlas do esporte, educação física e atividades físicas de saúde e lazer no Brasil. Rio de Janeiro: Shape; 2005.

44. Zanca G. A prática do remo em Florianópolis: retratos de uma sociedade em busca da modernidade no início do século XX. Rev Santa Catarina Hist. 2008:8.

45. Dias C. Primórdios do sport em terras brasileiras: um debate em aberto? Rev Bras Ci Esporte. 2011;33:265-71.

46. Melo V. Dicionário do esporte no Brasil: do século XIX ao início do século XX. Campinas: Autores Associados; 2007.

47. Melo V. Remo, modernidade e Pereira Passos: primórdios das políticas públicas de esporte no Brasil. Esporte Soc. 2006;3:1-21.

48. Prefeitura de Porto Alegre. Arquivo Histórico de Porto Alegre Moysés Vellinho. Porto Alegre: Prefeitura de Porto Alegre; 2008. [acesso 10 mar. 2013]. Disponível em: http://www2.portoalegre.rs.gov.br/smc/default.php?reg=10\&p_secao=19.

49. Museu da Comunicação Social Hipólito José da Costa: 30 anos. Porto Alegre; CORAG; 2005.

50. Clube de Regatas. A Gazetinha, Porto Alegre. 1895.

51. Mazo J, Assman A, Balbinotti C, et al. Associaçóes esportivas no Rio Grande do Sul: lugares e memórias. Novo Hamburgo: FEEVALE; 2012.

52. Araújo JRC. Imigração e futebol: o caso do Palestra Itália. São Paulo: Sumaré; 2000.

53. Bocketti GP. Italian immigrants, Brazilian football, and the dilemma of national identity. J Latin Am Studis. 2008;40:27.

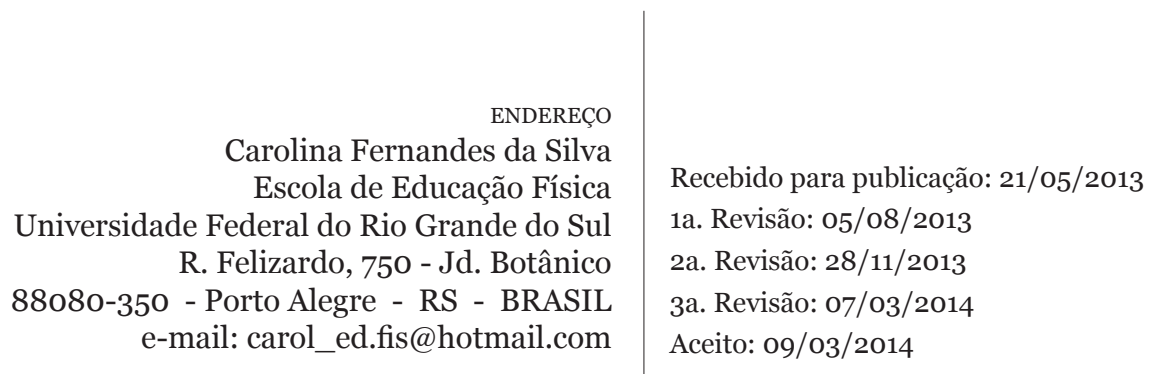

452 • Rev Bras Educ Fís Esporte, (São Paulo) 2014 Jul-Set; 28(3):441-52 